\title{
QUALITY OF SLEEP AND CHRONIC PAIN IN PATIENTS WITH RHEUMATOLOGICAL DISEASES
}

\author{
S. Slavov* \\ Department of Medical Psychology and Foreign Languages, Faculty of Medicine Trakia University, \\ Stara Zagora, Bulgaria
}

\begin{abstract}
Sleep disorders are common symptoms in patients with rheumatological diseases. Quality of sleep in patients with chronic pain affects their physical, psychological, cognitive, emotional and social functioning. Regardless of the large number of studies dealing with the relation between sleep and chronic pain, there is a deficit in the scientific literature when specific sleep disorders are associated with different rheumatological diseases. This review article is a literature review of the issue referring to the relation between the sleep disorders, quality of sleep and chronic pain in patients with rheumatological diseases. Presented is a large amount of scientific literature data reflecting the modern trends in the chronic pain-sleep disorders relation, as well as the psychosocial factors with an effect on the patients suffering from rheumatological diseases.
\end{abstract}

Key words: chronic pain-sleep quality relation, rheumatological diseases

\section{INTRODUCTION}

The modern understanding of pain is that it is a subjective multi-dimensional experience. Pain appears as a result of the neurophysiological integration of three main core aspects: sensorydiscriminative, affective-motivational and cognitive-evaluative (1). Pain is the initial sign of tissue damage warning the patients of an existing disease (2). Depending on their main concept, definitions of pain can be divided into three groups $(3,4)$ : Definitions based on the stimulus and its effect; Definitions based on the individual reflection of the effect of pain; Definitions which associate the stimuli and reactions with past experience and the perception and comprehension of the suffering caused by pain. The International Association of Pain defines pain as "an unpleasant sensory or emotional experience associated with actual or potential tissue damage, or described in terms of such damage" (5). Depending on its duration, pain is classified as acute or chronic.

\footnotetext{
*Correspondence to: Slavomir Slavov, Department of Medical Psychology and Foreign Languages, Medical Faculty, Trakia University, 11 Armejska Str., Stara Zagora, 6000 Bulgaria. Tel.: +359 885704291; E-mail: slavov_s@abv.bg
}

Chronic pain is the pain which lasts more than 3 months. It appears as a result of tissue damage and lasts after healing of the lesion causing that damage (6). The chronic disease has an obvious effect onto the physical, emotional, social, professional and financial state of the patient. The chronic disease is existent even when its symptoms have disappeared at some point (7). The chronic rheumatic pain has its specific features related with the localization, characteristics, duration, irradiation, what provokes it and what affects it, and last but not least, whether it is accompanied by other complaints (8). Three types of rheumatic pain are distinguished clinically: pain of the inflammatory type, pain of the mechanical type pain, and pain on palpation. (8) Rheumatological diseases are causing growing interest among the broad medical community and society due to their high prevalence and the increased risk of permanent inability (9). Rheumatological diseases cover more than 150 different nosological units, the most typical symptoms of which are pain and inflammation. This group of diseases continues to be a serious medical problem. Pain in rheumatic diseases is 
SLAVOV S.

associated with difficult self-care and motion, limited functionality, and increases patients' social isolation (10). According to data by the World Health Organization (WHO), muscles and skeleton related disorders are the most common chronic diseases in Europe. Approximately $50 \%$ of the adult population has symptoms of rheumatic pain lasting at least one week per month. It is considered that about $40 \%$ of women over the age of 50 will have different fractures due to osteoporosis. Between 15 and $20 \%$ of Europe's population suffer from various forms of rheumatic disease. To support this trend in the development and spread of rheumatic diseases, there is also a large-scale study conducted in the Netherlands, which found out that one out of 5 people over the age of 20 has a rheumatic complaint. The incidence and prevalence of rheumatic diseases is defined by the World Health Organization (WHO) as a growing problem (11).

\section{METHODS}

In connection with the scientific literature review on the topic, four reference databases (MEDLINE, ELSEVIER - Science Direct, SCOPUS, Springer) have been analyzed. The initial search resulted in finding 385 related articles. As search criteria were defined the article's publishing period (1970 - 2018), language (English) and the study group (adult patients). Key words used in the scientific literature search: quality of sleep, sleep disorders, chronic pain, chronic diseases, and rheumatological diseases.

\section{RELATION BETWEEN SLEEP AND PAIN}

In the scientific literature there are a number of studies establishing the relation between sleep and chronic pain $(12,13)$. In the context of the increasing amount of scientific data in support of the relation between sleep and pain, two fundamental questions are still not fully clarified: 1 . Is the relation between pain and sleep reciprocal or unidirectional? 2. Which are the mechanisms by which their relation is interpreted (14)? In support of the relation between sleep and pain, applied longitudinal analyses (15-17) have been found dealing how pain affects sleep. At the same time, in other analyses involving patients with fibromyalgia and rheumatological arthritis, evidence has been found for the effect of sleep onto pain (18). An interesting study dealing with the unidirectional relation between sleep and pain, has shown that women suffering from frequent sleep disorders (difficulties falling asleep) are more likely to develop fibromyalgia 10 years later (19). The prognostic result of this study is referred to other studies on the topic. One of them has established that the sleep disorder symptoms at baseline level significantly increase the risk of developing chronic diseases associated with muscular and skeletal pain over a period of 17 years (20). Further, the quality of sleep has predicted the chronic pain symptoms 15 months earlier (21). In support of the unidirectional relation and the prognostic effect of the sleep onto pain, modern studies suggest that sleep disorders predict affective responses related with pain in patients with rheumatological arthritis and fibromyalgia (22). In the studies dealing with the reciprocal relations, a tendency is observed suggesting that sleep disorder is a stronger predictor of pain than pain is of sleep disorder. A one-year longitudinal study involving patients with fibromyalgia has shown that sleep disorder is temporarily a prognostic factor with an effect on the increase of pain while at the same time there is no significant relation with the sleep disorder 1 year later (23). The significance of the effect is stronger with regard to the influence which sleep has onto pain, rather than vice versa. This means that the reduced sleep predicts an increase of pain one day earlier (24). Similar effects have been observed in studies involving patients with chronic pain in mature age and comorbidity of insomnia (25). In the present study, using a self-assessment questionnaire for the quality of sleep and actigraphy (method of sleep assessment), predicted are the pain warning signs one day earlier. The presented studies demonstrate that sleep disorders impair the long-term prognosis in patients with chronic pain in the muscular and skeletal system and affect their daily functioning.

\section{QUALITY OF SLEEP IN PATIENTS WITH RHEUMATOLOGICAL DISEASES}

Problems related to sleep are mainly observed as clinical complaints among the patients suffering from chronic pain. Although difficulties falling asleep and maintaining sleep are common in the general population, these are significantly more common in patients suffering chronic pain (26). Quality of sleep is a clinical construct used in the medicine of sleep and the studies in this field. It is almost universally accepted as a variable to differentiate among the good quality and poor quality sleep. In addition to this, it is used as a baseline measurement for the improvement in the treatment of sleep disorders. Sleep is not a 
one-dimensional system and it varies for each person. Integrated into the quality of sleep are general impressions, total sleeping time, tiredness after waking up, daily energy levels and functional damage (27). In the scientific literature, there are a number of studies which deal with the sleep disorders associated with rheumatological diseases. Most often the nature of these disorders is studied in patients with rheumatological arthritis. In a study involving patients suffering from rheumatological arthritis $(n=246), 60 \%$ of them have reported that chronic pain affects quality of sleep to some extent. Another 14\% have reported a severe and a very severe effect (28). In an ambulatory study on the nature of sleep disorders in patients $(\mathrm{n}=100)$ with rheumatological arthritis, insomnia (34\%) and frequent wake-ups at night (52\%) have been observed (29). Lavie et al. (30) have found out that quality of sleep measured by actigraphy is more deteriorated in patients with rheumatological arthritis compared to the control group of healthy individuals and patients with low back pain. Disorders associated with fragmentation of sleep have been observed in a study involving male patients with rhematological arthritis $(n=16)$ undergoing polysomnography (31). On the other side, the participants in the same study have not demonstrated objective evidence for existing insomnia, disorders related to wakeups or the restless feet syndrome. With regard to filling in the quality of sleep self-assessment questionnaire, no sleep disorders have been observed either. However, a daytime sleepiness has been established measured by The Multiple Sleep Latency Test (32). In $(n=14)$ male patients diagnosed with osteoarthritis and a control group of healthy individuals $(\mathrm{n}=16)$, by polysomnography, a more prolonged sleep duration at Stage 1 and a shorter sleep duration at Stage 2 have been observed in the group of patients (33). Sleep disorders are considered an additional clinical characteristic related to fibromyalgia since in a high percent of the patients with fibromyalgia, sleep disorders assessed both subjectively and objectively have been registered (34). In a large number of studies the percentage of people with fibromyalgia who have reported sleep disorders, varies between $62 \%$ and $75,6 \%$ compared with $9 \%$ to $31,1 \%$ for healthy individuals (35). Evidence to this is the study of Moldofsky et al. who describe the existence of sleep anomaly (sleep-awake rhythm disorder). This, in turn, results in a nonrestorative sleep in patients with fibromyalgia
SLAVOV S.

(36). The studies which aim to determine whether quality of sleep is independently related to the functional damage in patients with rheumatological arthritis, in line with the findings referring to chronic pain are of interest $(37,38)$. In the context of the above studies, it has been found out that the poor quality of sleep is associated with a more serious functional damage considering also variables such as age, sex, comorbidity with other diseases and duration of the rheumatological treatment. In addition to this, in another study (39), a model of mediation is proposed which shows that quality of sleep has an indirect effect onto the functional damage given its relation with the pain severity. This finding is in line with other modern evidence suggesting that sleep disorders are able to decrease the pain threshold in patients with rheumatological arthritis and healthy individuals (40-43). Deteriorated sleep quality is a common symptom in patients with rheumatological diseases and is observed in more than half of the patients $(44,45)$. Studies on sleep in patients with rheumatological diseases show that sleep interruptions are more frequent than the changes related to the sleep stages. Apart from that, falling asleep takes longer for such patients, they suffer frequent wake-ups at night and a feeling of sleepiness during the day (46). Difficulties related to sleep to a bigger extent are attributable to the articulated pain, depression and psychosocial stress (47). In an extensive study of Power et. al. (48) involving patients with arthritis and healthy individuals, it is observed that the percentage distribution of the insomnia and non-restorative sleep symptoms is respectively $24,8 \%$ and $11,9 \%$. These results are two times higher than those referring to the healthy individuals without arthritis. The effect of the disease is statistically significant which suggests that pain plays the role of a partial mediator in this relation. The presented scientific literature data clearly shows the interconnection between the sleep disorders, severity of chronic pain and the functional damage caused by the rheumatological disease. From the review of the scientific literature on this topic it also becomes clear that the number of the scientific studies establishing particular sleep disorders related to rheumatological diseases is insufficient. Another important aspect of the presented information reflects the influence of the psychosocial factors onto the quality of sleep and the chronic pain in patients with rheumatological diseases. 


\section{PSYCHOLOGICAL FACTORS}

Modern trends in the studies over the last two decades are focused on the role of the psychological factors in patients with rheumatological diseases and the chronic pain associated with the physical damage. The studies on the psychological factors are focused on three broad areas: emotional variables, cognitive variables and social variables. A large number of studies in this field have proven that depression is strongly correlated with chronic pain in patients with rheumatological diseases (49). In addition to this, it has been found out that pain is one of the strongest depression predictors in patients with rheumatological diseases (50). An interesting study supporting the abovementioned is the study of Kojima et al (51). It involves $(n=218)$ patients with rheumatological arthritis and has found out that the levels of depression and C-reactive protein are correlated. Nevertheless, each of them is an independent predictor of the intensity of chronic pain. In another similar study, Low et al. (52) also report that the somatic depression symptoms and the C-reactive protein level are significantly correlated in patients with rheumatological arthritis. One of the most important reasons for studying the emotional variables such as depression, anxiety and mental distress, is that they are able to affect the treatment results (53). An evidence for this is an extensive study $(n=6158)$ involving patients with osteoarthrosis who underwent a surgery for hip replacement where Rolfson et al. (54) have found out that the higher preoperative results referring to mental distress are significant predictors of patients' pain relief and satisfaction one year after the surgery. The scientific literature data shows that more detailed studies are needed to analyze the effects of the emotional variables upon development of painful rheumatological diseases, as well as upon exacerbation of their symptoms. The individual perceptions, dysfunctional thoughts, beliefs, expectations as well as the coping strategies, are able to affect chronic pain in patients with rheumatological diseases (55-57). In connection with the patients' evaluation of how they cope with the disease, Sinclair and Wallston (58) have developed a methodology for flexible (resilient) coping (tendency to cope with stress in a flexible way) and have found out using this methodology helps patients with rheumatological arthritis cope with chronic pain more successfully. In addition to all of the above said, Smith and Zautra (59) have found
SLAVOV S. out that the higher baseline resistance is associated with much higher levels of positive social interactions in patients with rheumatlogical arthritis and osteoarthrosis. Rheumatological diseases are affected also by the social context of the patients. The social support appears to be an important factor for their adaptation to the disease. Patients with rheumatlogical diseases could benefit from the emotional social support, informational social support and the behavioral sources of social support (60). The social context which ensures support to the patients can help them adapt better to the disease. The detailed studies associated with the psychological factors with an effect on the patients with rheumatological diseases are an important element of their overall treatment. Analysis of these factors in one with the functional damages caused by the disease is part of the work of a wide circle of specialists directly involved with this group of patients. On the basis of the studies in this area, effective psychological methods for pain relief are also elaborated.

\section{CONCLUSION}

Chronic rheumatological diseases affect seriously patient's physical, psychological and social functioning. Rheumatological diseases are a serious medical problem and are the most wide spread chronic diseases among the European population. The interrelation between sleep and pain highlights the tendency that sleep, respectively its quality, is a pain predictor and is related with the pain intensity and severity. The data from the studies presented clearly shows that sleep disorders deteriorate the long-term prognosis in patients with rheumatological diseases and have a direct effect onto their daily functioning. Deteriorated sleep quality in patients with rheumatological diseases is most often manifested by difficulties falling asleep, frequent wake-ups, insomnia symptoms, increased daytime sleepiness and a nonrestoration after sleep. On the basis of the review on the scientific literature sources on the topic, it has been found out that the number of similar studies on the rheumatological conditions related to specific sleep disorders and their effect on the overall patient's functioning is inadequate. The psychosocial factors - emotional, cognitive and social variables, are an integral part of the studies in this field. Understanding the complexity and the number of factors with an effect on the rheumatological diseases, is a starting point for a more effective treatment in a medical, 
psychological and psychotherapeutic context.

\section{ACKNOWLEDGMENT}

This study has received no financial support.

\section{REFERENCES}

1. Yong, R.J., Nguyen, M., Nelson, E., Urman , R.D.,Pain medicine: An essential review. Springer, 2017.

2. Reshkova, V., Rashkov, R., Milanov, I., Z. Kolarov., Pain. Ed:Reshkova, V., Sofia:Medicine and psysical culture, 2014.

3. Wall, P., Melzack,R., Bonica, J., (Edrs). Textbook of pain. Third Edition, Churchill Livingston, London, 1994.

4. Spranger, G., Hayt, K., R Heidenhofer. Pain Management. In : Emergency medicine, Third Edition. Kravic, TC., Warner, CG., Jacobs, LM. (Edrs). Raven Press, New York., pp 877-890,1993.

5. Boyd, D.B., Taxonomy and classification of pain. In: Handbook of pain management. Tollison, C.D., Sattertwaite, J.R., Tollison, J.W., eds., Williams \& Wilkins, Baltimore.,pp 7-10, 1994.

6. Milanov,I., National Consensus for Diagnosis and Treatment of Neurological Determined Pain. Cephalgia, 17: 1:9-64, 2015.

7. Petkova, M., Subjective well-being and health. Stara Zagora: Publishing house Kota, 2002.

8. Kolarov, Z., Pathophysiological Mechanisms, Clinical Characteristics and Therapeutic Approach (Guidance for Specialists). MLN Sofia EOOD,2003

9. Nikolov, N., Panchovska, M., Kolarov, Z., Economic analyzes in rheumatology. Rheumatology, 4: 5-14,2011.

10.Atanasov, A., Pain and its treatment. In: Panchovska,M., The pain in rheumatology, Bone and joint pain. Medical Publishing House "Vasil Aprilov", Plovdiv., pp 216229, 2007.

11.Nikolov, N., Panchovska, M., Kolarov, Zl., Spreading and Structure of Rheumatic Diseases. Medical Review, 49: 4, 22-25, 2013.

12.Morin, CM., LeBlanc, M., Daley, M., Gregoire, JP., Merette, C., Epidemiology of insomnia: Prevalence, self-help treatments, consultations, and determinants of helpseeking behaviors. Sleep Med, 7:123-130, 2006.

13.Smith, MT., Haythornthwaite, JA., How do sleep disturbance and chronic pain interrelate? Insights from the longitudinal and cognitive-behavioral clinical trials literature. Sleep Med Rev, 8:119-132, 2004.
SLAVOV S.

14.Finan, PH., Goodin, BR., Smith, MT., The association of sleep and pain: an update and a path forward. J Pain, 14(12):1539-52, 2013.

15.Affleck ,G., Urrows, S., Tennen, H., Higgins, P., Abeles,M., Sequential daily relations of sleep, pain intensity, and attention to pain among women with fibromyalgia. Pain, 68: 363-368, 1996.

16.Drewes, AM., Nielsen, KD., Hansen, B., Taagholt, SJ., Bjerregard, K., Svendsen, L., A longitudinal study of clinical symptoms and sleep parameters in rheumatoid arthritis. Rheumatology (Oxford), 39:12871289, 2000.

17.Raymond , I., Nielsen, TA., Lavigne, G., Manzini, C., Choiniere, M., Quality of sleep and its daily relationship to pain intensity in hospitalized adult burn patients. Pain, 92: 381-388, 2001

18.Stone, AA., Broderick, JE., Porter, LS., Kaell, AT., The experience of rheumatoid arthritis pain and fatigue: Examining momentary reports and correlates over one week. Arthritis Rheum, 10:185-193, 1997.

19.Mork, PJ., Nilsen, TI., Sleep problems and risk of fibromyalgia: Longitudinal data on an adult female population in Norway. Arthritis Rheum, 64:281-284, 2012.

20.Nitter, AK., Pripp, AH., Forseth, K., Are sleep problems and non-specific health complaints risk factors for chronic pain? A prospective population-based study with 17 year follow-up. Scand J Pain, 3:210-217, 2012.

21.Davies, KA., Macfarlane, GJ., Nicholl, BI., Dickens, C., Morriss, R., Ray, D., McBeth, J., Restorative sleep predicts the resolution of chronic widespread pain: Results from the EPIFUND study. Rheumatology (Oxford) , 47:1809-1813, 2008.

22.Hamilton, NA., Catley, D., Karlson, C., Sleep and the affective response to stress and pain. Health Psychol, 26:288-295, 2007.

23.Bigatti, SM., Hernandez, AM., Cronan, TA., Rand, KL., Sleep disturbances in fibromyalgia syndrome: Relationship to pain and depression. Arthritis Rheum, 59:961-967, 2008.

24.Edwards, RR., Almeida, DM., Klick, B., Haythornthwaite, JA., Smith, MT., Duration of sleep contributes to next-day pain report in the general population. Pain, 137:202-207, 2008.

25.Tang, NK., Goodchild, CE., Sanborn, AN., Howard, J., Salkovskis, PM., Deciphering the temporal link between pain and sleep in 
a heterogeneous chronic pain patient sample: A multilevel daily process study. Sleep, 35(5):675-87A, 2012.

26.Menefee, LA., Cohen, M M., Anderson, WR., Doghramji, K., Frank, E. D., Lee, H., Sleep disturbance and nonmalignant chronic pain: A comprehensive review of the literature. Pain Medicine, 1:2, 156$172,2000$.

27.Crawford, Megan R., Ong, C., There Are Two Sides to Every Question: Exploring the Construct of Sleep Quality. The Journal of Clinical Psychiatry, 76:6, 822-823,2015.

28.Nicassio, PM., Wallston, KA., Longitudinal relationships among pain, sleep problems, and depression in rheumatoid arthritis. $J$ Abnorm Psychol, 101:514-520, 1992.

29.Hart, FD., Taylor, RT., Huskisson, EC., Pain at night. Lancet, 1:881-884, 1970.

30.Lavie, P., Epstein, R., Tzischinsky, O., et al., Actigraphic measurements of sleep in rheumatoid arthritis: comparison of patients with low back pain and healthy controls. $J$ Rheumatol, 19:362-365, 1992.

31.Mahowald, MW., Mahowald, ML., Bundlie, SR., Ytterberg, SR., Sleep fragmentation in rheumatoid arthritis. Arthritis Rheum, 32:974-982, 1989.

32.Carskadon, MA., Dement, WC., Daytime sleepiness: quantification of a behavioral state. Neurosc Biobehav Rev, 11:307$317,1987$.

33.Leigh, TJ., Hindmarch, I., Bird, HA., Wright, V., Comparison of sleep in osteoarthritic patients and age-and sexmatched healthy controls. Ann Rheum Dis, 47:40-42, 1988.

34.Wolfe, F., Smythe, HA., Yunus, MB., Bennett, RM., The American College of Rheumatology 1990 criteria for the classification of fibromyalgia. Arthritis Rheum, 33:160-172, 1990.

35.Yunus, MB., Masi, AT., Aldag, JC., A controlled study of primary fibromyalgia syndrome: clinical features and association with other functional syndromes. $J$ Rheumatol,16(suppl 19):62-71, 1989.

36.Moldofsky, HM., Scarisbrick, PB., England, RB., Smythe, HM., Musculoskeletal symptoms and nonrem sleep disturbance in patients with "fibrositis syndrome" and healthy subjects. Psychosom Med, 37:341-351, 1975.

37.McCracken, LM., Iverson, GL., Disrupted sleep patterns and daily functioning in patients with chronic pain. Pain Res Manag, 7:75-79, 2002.
SLAVOV S.

38.Naughton, F., Ashworth, P., Skevington, SM., Does sleep quality predict pain-related disability in chronic pain patients? The mediating roles of depression and pain severity. Pain, 127:243-252,2007.

39.Luyster, FS., Chasens, ER., Wasko, MC., Dunbar-Jacob, J., Sleep quality and functional disability in patients with rheumatoid arthritis. J Clin Sleep Med, 7:49-55, 2011.

40.Wolfe, F., Michaud, K., Li, T., Sleep disturbance in patients with rheumatoid arthritis: evaluation by medical outcomes study and visual analog sleep scales. $J$ Rheumatol, 33:1942-1951,2006.

41.Lee, YC., Chibnik, LB., Lu, B., et al., The relationship between disease activity, sleep, psychiatric distress and pain sensitivity in rheumatoid arthritis: a cross-sectional study. Arthritis Res Ther, 11:R160,2009.

42.Nicassio, PM., Wallston, KA., Longitudinal relationships among pain, sleep problems, and depression in rheumatoid arthritis. $J$ Abnorm Psychol, 101:514-520, 1992.

43.Roehrs ,T., Hyde, M., Blaisdell, B., Greenwald, M., Roth, T., Sleep loss and REM sleep loss are hyperalgesic. Sleep, 29:145-151, 2006.

44.Van Hoogmoed, D., Fransen, J., Bleijenberg, G., van Riel ,P., Physical and psychosocial correlates of severe fatigue in rheumatoid arthritis. Rheumatology, 49: 1294-1302, 2010.

45.Taylor-Gjevre, RM., Gjevre, JA., Nair, B., Skomro, R., Lim, HJ., Components of sleep quality and sleep fragmentation in rheumatoid arthritis and osteoarthritis. Musculoskel Care, 9: 152-159,2011.

46.Treharne, GJ., Lyons, AC., Hale, ED., Douglas, KM., Goodchild, CE., Booth, DA., Kitas, GD., Sleep disruption frequency in rheumatoid arthritis: perceived stress predicts poor outcome over one year. Musculoskeletal Care, 5: 51-64, 2007.

47.Albayrak Gezer, I., Balkarli, A., Can, B., et al., Pain, depression levels, fatigue, sleep quality, and quality of life in elderly patients with rheumatoid arthritis. Turk $J$ Med Sci, 47:3, 847-853, 2017.

48.Power, JD., Perruccio, AV., Badley, EM., Pain as a mediator of sleep problems in arthritis and other chronic conditions. Arthritis Rheum, 53:911-919, 2005.

49.Wolfe, F., Michaud, K., Predicting depression in rheumatoid arthritis: the signal importance of pain extent and 
fatigue, and comorbidity. Arthritis Rheum, 61:667-673, 2009.

50.Covic, T., Tyson, G., Spencer, D., Howe, G., Depression in rheumatoid arthritis patients: demographic, clinical, and psychological predictors. J. Psychosom. Res, 60: 469 476,2006.

51.Kojima, M.,et al., Depression, inflammation, and pain in patients with rheumatoid arthritis. Arthritis Rheum, 61:1018-1026, 2009.

52.Martire, LM., et al., Older spouses' perceptions of partners' chronic arthritis pain: implications for spousal responses, support provision, and caregiving experiences. Psychol. Aging, 21:222-230, 2006.

53.Keefe, FJ., Somers, T J., Psychological approaches to understanding and treating arthritis pain. Nat. Rev. Rheumatol, 6:210216, 2010.

54.Rolfson, O., Dahlberg, LE., Nilsson, JA., Malchau, H., Garellick, G., Variables determining outcome in total hip replacement surgery. J. Bone Joint Surg. $B r, 91: 157-161,2009$.
SLAVOV S.

55.Jensen, MP., Turner, JA., Romano, JM., Karoly, P., Coping with chronic pain: a critical review of the literature. Pain, 47: 249-283, 1991.

56.Villemure, C., Bushnell, MC., Cognitive modulation of pain: how do attention and emotion influence pain processing? Pain, 95:195-199, 2002.

57.Seminowicz, DA., Davis, KD., A reexamination of pain-cognition interactions: implications for neuroimaging. Pain, 130:8-13, 2007.

58.Sinclair, VG., Wallston, KA., The development and psychometric evaluation of the Brief Resilient Coping Scale. Assessment, 11:94-101, 2004.

59.House, J., Kahn, R. In: Cohen, S., Syme, SL (eds), Social Support and Health. Academic Press, New York, pp 83-108 1985.

60.Li, X., Gignac, MA., Anis, A H., Workplace, psychosocial factors, and depressive symptoms among working people with arthritis: a longitudinal study. J. Rheumatol, 33: 1849-1855, 2006. 